Sonic Scope: New Approaches to Audiovisual Culture • Issue One

\title{
Revisiting Vangelis: Sonic Citation and Narration in the Score for Blade Runner 2049
}

James Denis Mc Glynn ${ }^{1}$

${ }^{1}$ University College Cork

Published on: Oct 06, 2020

DOI: $10.21428 / 66 f 840 a 4.9$ dead577

License: Creative Commons Attribution 4.0 International License (CC-BY 4.0). 


\section{ABSTRACT}

Revisiting Vangelis: Sonic Citation and Narration in the Score for Blade Runner 2049

James Denis Mc Glynn, University College Cork

In August 2016, it was announced that Icelandic composer Jóhann Jóhannsson was to compose the score for Denis Villeneuve's highly anticipated sequel to Ridley Scott's Blade Runner (1982). However, just weeks in advance of the film's worldwide premiere, it became apparent that Jóhannsson's involvement in the project had been terminated, making way for an apparent takeover by composers Hans Zimmer and Benjamin Wallfisch. The popular narrative that developed to explicate this seemingly sudden shift was that Jóhannsson's music didn't adequately cite Vangelis' original score for the 1982 Blade Runner. This article explores the extratextual musical citation present in Zimmer and Wallfisch's score for Blade Runner 2049. While only one cue from the original Blade Runner is directly cited in the film, I propose that the composers adopt Vangelis' 1982 soundtrack as a primary compositional referent for their whole score and that his source material permeates the entire film: melodically, harmonically, and sonorously. By separately addressing the film's (i) sonorous and (ii) motivic citation of Vangelis' original material for Blade Runner, I hope to highlight the diverse array of narrational, structural and musical functions that musical citation can facilitate in scoring practice, even without audience identification of the source context.

\section{Introduction}

In August 2016, it was revealed that Icelandic composer Jóhann Jóhannsson was to compose the score for Denis Villeneuve's highly anticipated 2017 sequel to Ridley Scott's Blade Runner (1982), an announcement that was met with much excitement amid the secrecy that shrouded the project. Jóhannsson had reportedly been recruited for the project for quite some time and, having commenced work on the soundtrack in June, had begun submitting music that his long-time collaborator Villeneuve described as "insane, experimental, powerful tracks that blew [their] minds." was later announced that Hans Zimmer was to serve as an additional collaborator for the soundtrack and, just weeks in advance of the film's worldwide premiere, it became apparent that Jóhannsson's involvement in the project had been terminated, making way for an apparent takeover by Zimmer and Benjamin Wallfisch. ${ }^{2}$ It is unknown how much material Jóhannsson generated for the project, and his contributions remain unreleased and unheard. Based on the content of Zimmer and Wallfisch's score and Villeneuve's comments on this reassignment, we might deduce that Jóhannsson's music did not adequately channel Vangelis' original score for the 1982 Blade Runner in a way which was believed 
would embody the spirit of the franchise or appease its long-standing fanbase. $\underline{3}$ In this sense, this curious and seemingly sudden shift might be seen as a reflection of Villeneuve's resolve "to go back to something closer to [original Blade Runner composer] Vangelis." $\underline{4}$

There is obvious intrigue to unpacking the circumstances that surrounded this very public change in personnel, especially given both Jóhannsson's contractual inability to comment on the situation and his tragic and untimely passing in February 2018. $\underline{5}$ Of course, history has shown that such reassignments are commonplace in the production of Hollywood film scores, as was the case for Bernard Herrmann's replaced score for The Magnificent Ambersons (Orson Welles, 1942) and, perhaps most famously, Alex North's unused music for 2001: A Space Odyssey (Stanley Kubrick, 1968). 6 However, Villeneuve's foray into the Blade Runner franchise presents us with a compelling and nuanced exemplar of these circumstances and their far-reaching effects. Going beyond issues of mere curiosity, I propose that the intriguing narrative concerning Jóhannsson's dismissal (for reasons apparently concerning musical citation) and the resultant musical content of the Zimmer and Wallfisch score for Blade Runner 2049 (hereafter referred to as 2049) invite us to look deeper into the issues of adaptation and rearrangement of pre-existing musical material that often arise in narrative film. This science fiction sequel demonstrates many of the creative consequences which the careful adaptation of pre-existing music can occasion in film: narratively, structurally and musically. Such qualities prominently characterise the film from its outset and, in foregrounding the apparent relevance of pre-existing sources to its filmmakers, 2049's debts to its precursor are seen to visibly reshape the fabric of the narrative itself.

So much writing on film music prioritises the source context of pre-existing music in accounting for its meaning-formation. ${ }^{-}$This is of course predicated on the notion that referentiality is not merely a defining characteristic of pre-existing music, but actively flaunted by it. $\underline{8} 2049$, a film which so vibrantly illustrates the myriad intricate ways that pre-existing music can manifest itself in the score, could equally be said to flaunt its referentiality in this way: the film's final cue "Tears In The Rain" is a replication of a cue from the original Blade Runner soundtrack, heard in its original tonality and in a faithful approximation of Vangelis' synthesised instrumentation. Audience recognition of the source context is undoubtedly the desired effect of this inclusion and is made explicit by its placement in the film ("Tears In The Rain" is directly transposed from the emotional epicentre of Scott's original film onto that of Villeneuve's sequel). Quotation with such self-evident narrative intention does not appear to necessitate much immediate analysis. However, what is more noteworthy is how Zimmer and Wallfisch adopt Vangelis' 1982 soundtrack as a primary compositional referent for their whole score. Although "Tears In The Rain" is the only composition attributed to Vangelis in 2049, a closer analysis of the score reveals that Vangelis' source material permeates the entire film, whether melodically, harmonically, intervallically, or even in the score's sonorous qualities and instrumentation. ${ }^{2}$ In fact, it 
is by way of these qualities of sonority and instrumentation, arguably the less immediately "salient aspects of a composition," that 2049 cultivates some of its most elaborate evocations of Vangelis' source material. $\underline{10}$

In this article, I will explore extratextual musical citation in the score for 2049 , a film which is characteristically referential, yet conceals its debts to its precursor in such a way that it becomes untethered from its source context. By examining the array of narrational, structural and musical functions that are visibly facilitated by 2049's adaptation of Vangelis, I hope to underline how "[recognition] will not always be a filmmaker's primary reason for employing pre-existing music" and that musical citation can facilitate an array of functions in scoring practice which often supersede audience identification of the source. 11 I will also account for 2049's apparent attempts to synthesise elements of music, sonority, instrumentation and sound design in its sonic citation of Vangelis, forging a timbral emphasis which bears crucial semiotic significance in its communication of the film's narrative. Ultimately, by exploring the semiotic connotations of 2049's sonorous qualities and hyperorchestral textures, I hope to highlight the equal footing that timbre shares with aspects of melody, harmony and motivic content in transmitting narrative information, a quality that Villeneuve's Blade Runner instalment actively plays upon in its sonic citation of Ridley Scott's 1982 film.

The theoretical basis of this article situates 2049 in the context of several current discussions in film music scholarship. In particular, I engage with the discourse of hapticity in film music and film sound (as discussed by Miguel Mera and Lisa Coulthard respectively), the recurring notion of hyperorchestration and recent scoring trends which appear to "[blur] the line between music and sound design." $\underline{12}$ Throughout the discussion, I draw extensively on concepts and terminology originating from such discourse, with my later analyses relying on close harmonic and motivic analysis of the film's musical cues. In lieu of an officially published 2049 score, my analysis of the film's cues necessitated transcription of Blade Runner and 2049's most prominently shared musical material, presented here in the form of notated piano reductions (see Figures 3-5 and 7-9). Finally, it is important to note that while I frequently attribute the score to Zimmer and Wallfisch throughout this article, such a designation should not be seen as dismissive of the contribution of the film's sound editors and sound designers in communicating the sonic spirit of the Blade Runner franchise. While there is no doubt that the collaboration of the whole sound team was essential in achieving this feat, my references to "Zimmer and Wallfisch's score" have simply been a concession to convenience and clarity in unravelling the film's composed music from other contributing elements present in the soundtrack (and indeed, because it is under those composers' names that the 2049 soundtrack has been commercially released by Epic/ASG).

It is in this profound symbiosis of 2049's sonorous and motivic elements which I argue the film's most potent evocation of Vangelis is formed. However, in order to fully grasp why this relationship was to be such a prominent consideration in sculpting 2049's soundtrack, it is first imperative to address 
the legacy upheld by the original Blade Runner's audiovisual representation of dystopia, a sonic inheritance which is as inherently sonorous as it is musical. By accounting for this legacy and situating it amid the contemporary approaches to film sound which best articulate its importance, I hope to provide a robust contextual and theoretical basis for the detailed musical analyses that follow.

\section{Citation of a Legacy}

It would be difficult to generate any useful insights into 2049 without first acknowledging the sheer scale of the legacy that accompanies Ridley Scott's original 1982 film in the histories of cinema, science fiction and film music (see Figure 1).

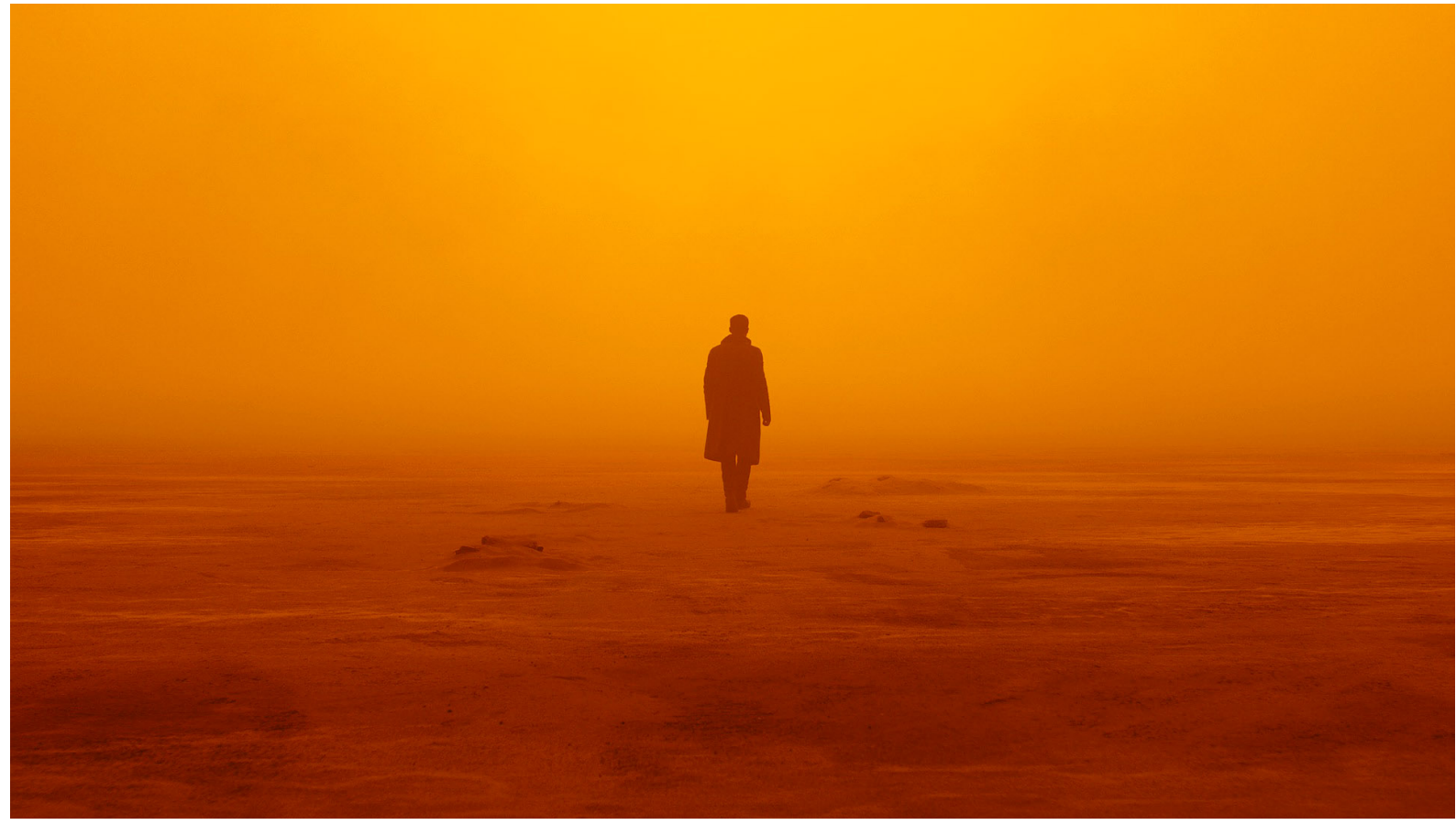

Figure 1. 2049's director and composers have all spoken about the challenges they faced in revisiting the sights and sonorities of Blade Runner (1982), a film in which, according to Villeneuve, sound occupies the same "aesthetic zone" as its other characteristics.

Scott's film carries with it an enduring impact that is, crucially to this discussion, inherently audiovisual. Media historian Norman Klein vividly encapsulates the sensory inheritance left by Scott's original film and how Blade Runner became "a paradigm for the future of cities, for artists across disciplines," continually channeled in depictions of dystopian futures across screen media. $\underline{13}$ Crucially, he highlights how inextricably connected the film's visual aesthetic is to its soundtrack, describing how "the hum of that Vangelis score against the skyline of L.A. in 2019, as the film opens, continues to leave a strange impact on artists and filmmakers." $\underline{14}$ Consequently, this audiovisual legacy was to be an 
inevitable consideration for those tasked with scoring the film's sequel. In an interview with Zach Laws, Benjamin Wallfisch emphasises how central these concerns were from the outset. He describes how the first conversations he shared with Zimmer and Villeneuve recognised "just how intertwined Vangelis [was] with the fabric of the original film," such that "it's almost impossible to imagine it without that score." $\underline{15}$ Thus, the approach they would then adopt for 2049 would be about "taking that great respect and love of that music" and adapting it to the needs of this very different narrative. According to Wallfisch, he and Zimmer aspired to create "a score which [paid] its respects to Vangelis," while still remaining "something new."

Based on our limited insight into the composers' intentions for this film, it might also be argued that, although narratively speaking a sequel, 2049 ultimately amounts to something far more akin to a remake: of the soundscape, visual palette and even the narrative pace and trajectory of Ridley Scott's original. Villeneuve was aware of this possible outcome, acknowledging the many difficulties inherent to "[taking] someone else's dream, to take someone else's characters [and] aesthetics." 17 Notably, he emphasises how central recreating the soundtrack was in these considerations, given that in the original Blade Runner, sound occupies the same "aesthetic zone" as other aspects of the film. $\underline{18}$

For those familiar with the 1982 work, it may well be said that this score achieves Wallfish's ambition for the 2049 soundtrack to reflect "something new, but ... still firmly rooted in that incredible sound world that Vangelis created." $\underline{19}$ Here, even the term "sound world" carries with it an emphasis on texture, with associations of sonority, tessitura, harmonic density and tempi. Such characteristics of the original score are audibly indispensable facets of 2049's sonic representation of Blade Runner. However, less immediately apparent are the ways in which the 2049 score incorporates the same musical material as Vangelis' 1982 soundtrack. Musical content from the original film pervades the score in a manner resembling complex recomposition, suggesting an underlying compositional approach in which motivic transformation shares an equal foothold with the score's audible sonorous channelling of the original Blade Runner. The 2049 soundtrack is harmonically anchored in motivic content Vangelis established thirty-five years previously, cited in a nuanced manner that continually skirts the periphery of our recognition.

It is around these two forms of reference which I have structured this paper's textual analyses and distinguished 2049's citation of both (i) textural or "sonorous" qualities and (ii) motivic content. Such a categorisation brings to mind more traditional musical language, in particular Leonard Meyer's similar dichotomy of primary and secondary stylistic musical parameters. $\underline{20}$ As a case study, 2049 serves to expose the limitations inherent to such an approach, especially the division implicit in such terms as "primary" and "secondary," which convey a hierarchy that is completely at odds with contemporary music. $\underline{21}$ Such a hierarchal perspective also contradicts recent approaches to the film score, many of which emphasise the equal footing that sonority and timbre share with the score's melodic and 
harmonic qualities. This dual-emphasis can be seen in discourse on both the materiality and so-called hapticity of film music, as well as Sergi Casanelles' cogent description of hyperorchestration and the near-infinite options that he argues sound processing, micing practices and digital instruments afford film composers as a means of creating variation in their soundtracks. $\underline{22}$

Of course, at first glance, my resolve to divide analyses between the film's sonorous and motivic citation of Vangelis may seem to inadvertently reinforce these more traditional distinctions between elements of harmony and sonority that I have set out to challenge. However, my motivations are quite different. Structuring my analysis in this way, I have endeavoured to erode - not reinforce - any implied hierarchal valorisation. It is by handling issues of timbre and melody/harmony in turn and with equal depth that I hope to emphasise the equal footing shared by these qualities in their communication of the 2049 narrative. This is also a practical consideration: should we accept the often "seamless merging of music with sound design" present in contemporary film and the resultant ambiguity that exists between issues of timbre and melody/harmony, the characteristics of the 2049 score inevitably become interwoven in complex, overlapping and seemingly imperceptible ways. $\underline{23}$ In this respect, dividing the textual analyses of 2049 in this way has been a conscious attempt to untangle these closely knitted qualities and enhance the clarity of the argument for the reader. It does not imply any bias on what I believe to be inherently mutualistic and equally-weighted qualities of the film score.

By structuring my argument around this profound dual-emphasis and by employing contemporary approaches to film sound alongside more traditional musical analysis, I hope to generate a more complete picture of the citation present in the 2049 score and emphasise the prominent equivalence that both sonic and harmonic qualities share in their contribution to the narrative (and indeed film scoring more generally). It is with these realities of contemporary scoring practice in mind that I will first turn to the score's sonorous citation of Vangelis.

\section{Citing Vangelis in 2049}

\section{(i) Sonic Qualities}

While musicologist Joanna Demers has designated sonority as a less salient musical characteristic, sonorous qualities comprise 2049's most prominent and immediately recognisable aural debts to

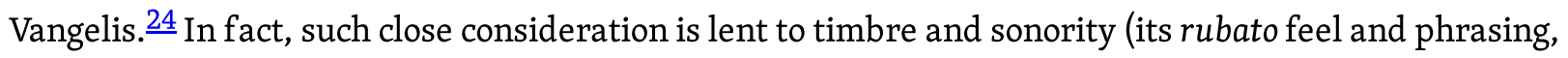
four-note cell structure, tempi and dynamics) $\underline{25}$ that this case study serves to exemplify the shift from 
Meyer's hierarchal approach quite persuasively. Wallfisch labels these textural and dynamic qualities as being evocative of the "majesty of the original score, the way it breathes," describing how "it sometimes feels almost improvised, it has that kind of horizontal attitude." $\underline{26}$ Jóhannsson references these same qualities when discussing the deep-seated influence of Vangelis on his unheard score and his career more broadly, citing "the way [Vangelis] uses space in his music ... his use of very strong and simple phrases" and, in particular, his use of reverberation. $\frac{27}{2}$ Here, Jóhannsson pinpoints facets of Vangelis' style which illustrate the hyperorchestration techniques and technologies discussed by Casanelles $\underline{28}$ and how, through the minutiae of recording and audio production, the composer can elicit narrative signification and extratextual citation whereby "music is able to imply a meaning that would have otherwise required harmonic or instrumental variation." $\underline{29}$ Indeed, the signifying potential of such musical qualities as timbre, tempi and dynamics has long been acknowledged by music semioticians such as Thomas Turino. $\underline{30}$ However, here Casanelles proposes that films which incorporate such techniques have only recently begun to foreground and capitalise on the importance of sound processing as an important signifier in Hollywood film scoring, where "[meaning is generated] just by applying aural modifications to the musical content of a piece." $\underline{11}$ Indeed, while it is true that sonority does serve as an indispensable signifier in the original Blade Runner, my analysis of its sequel (along with personal accounts from the filmmakers and the film's audible merging of the soundtrack's sonorous qualities with aspects of melody and harmony) speaks to an awareness and intentionality behind 2049's symbiosis of music and sound design which cannot be said of the original film.

Similarly, it would be impossible to discuss sonority as a signifier of the Blade Runner franchise without examining the instrumentation which has become synonymous with both films and their dystopian prophecy, as Klein's account illustrates. $\underline{32}$ Instrumentation is particularly foregrounded by the films, especially given the 1982 soundtrack's initial departure from classical Hollywood scoring, its use of popular instrumentation and, most importantly, the semiotic weight attached to that popular sonority. Vangelis' use of the synthesiser is evidence in itself of popular instrumentation's reliance on timbre as a primary signifier, the importance of which cannot be overemphasised, as Jeff Smith reminds us. $\underline{33}$ This citation of Vangelis' instrumentation was to be inevitable for those tasked with scoring 2049, a film which Wallfisch depicts as having, after several attempts, "rejected an orchestra." $\underline{34}$ The film's two composers and director have all separately stated that the Yamaha CS-80 synthesizer was to be "the star of the show." Despite what has long been acknowledged as synthesizers' "almost limitless ability to create sound, unique and otherwise," both Blade Runner films demonstrate how the quite specific semiotic capacity of the synthesizer is not diluted by the breadth of its sonorous palette. $\frac{35}{3}$ This is reinforced by the importance Zimmer and Wallfisch place on Vangelis' instrumentation in the communication of 2049's narrative, as well as both films' use of popular 
sonorities which, unlike in classical Hollywood scoring, bear a distinct character which, according to Smith, "is not inherent in its form, but rather the materiality of its sound." $\underline{6}$

This issue of "materiality" highlighted by Smith raises a recurrent and topical point of study for scholars of both film sound and film music in accounting for sonorous qualities in cinema, especially in discussions concerning haptic music. A prominent idea in contemporary approaches to film, the concept of hapticity offers us a valuable framework with which we can tersely account for Zimmer and Wallfisch's prominent sonorous citation of Scott's original Blade Runner. Drawing on the description of haptic sound put forth by Lisa Coulthard (in itself an extension of Laura Marks' notion of haptic visuality), the concept of haptic music, or hapticity, is predicated on the idea that "film is grasped not solely as an intellectual act but by the complex perception of the body as a whole." $\underline{7}$ In the field of film music studies, hapticity has been adopted to describe scores which have consciously foregrounded the materiality of sound and music production, often by way of what Miguel Mera describes as a “'dirtiness"' formed through "the use of microtones, clusters, and aleatoric and extended instrumental techniques." $\underline{38}$ Ultimately, such scores are said to evince "a possible reorientation of cinema from visual to haptic appropriation" or embodied viewership.

2049 is populated by numerous instances which might be said to invite such an embodied engagement with the film, especially given Villeneuve's resolve to frequently twin the score's synth sonorities with violent or bodily imagery (see Figure 2). 


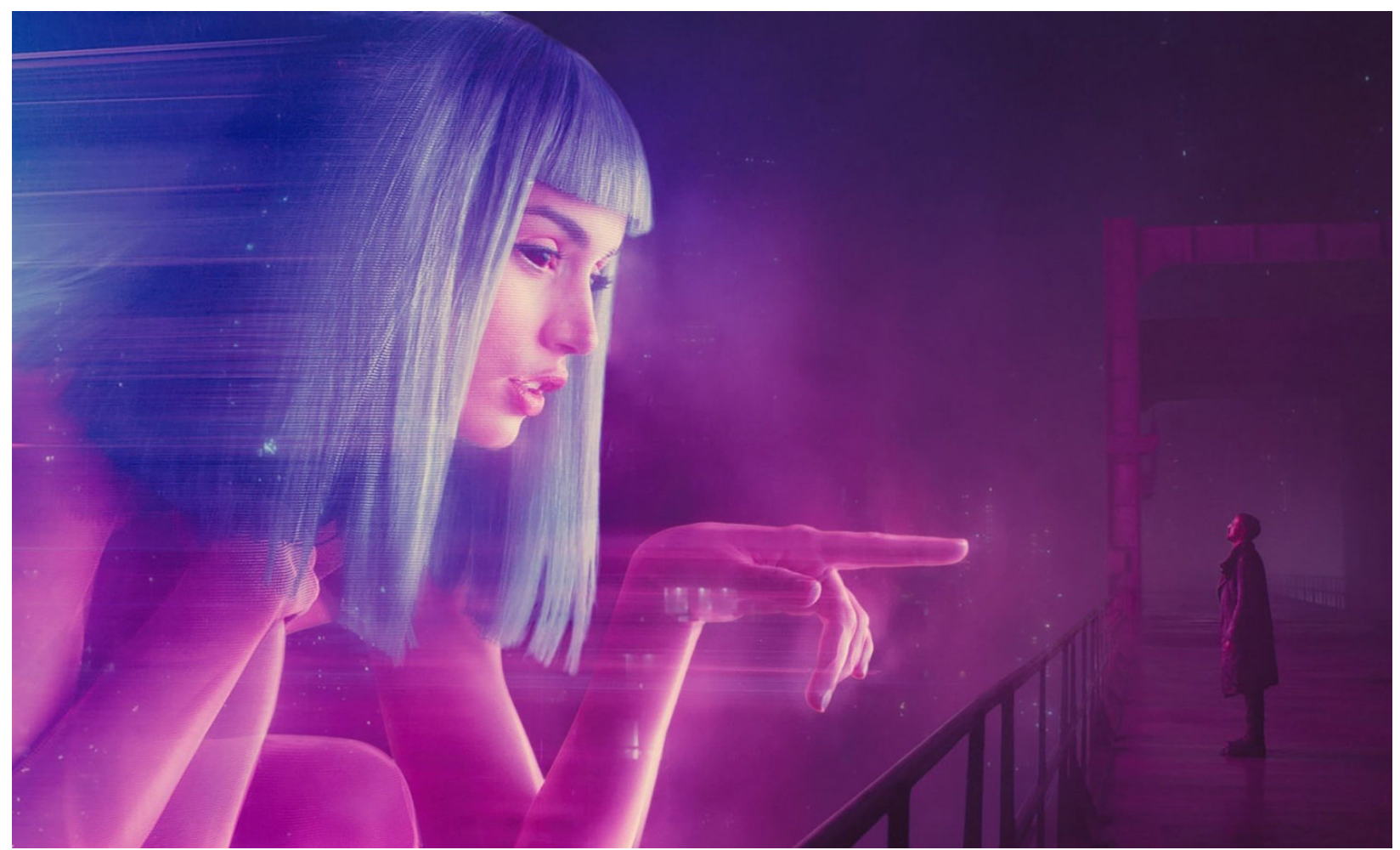

Figure 2. In line with recent discourse on materiality and hapticity in the film soundtrack, 2049 often pairs its most prominently hyperorchestral sonorities with depictions of the human body or graphic violence.

This is apparent from the film's opening scene, in which the score's first overwhelming synth swell (see Figure 5, measure 1) accompanies a full-screen close-up of a human eye. $\frac{39}{}$ The materiality and motion of this shot's eye movement is emphatically coloured by the score's first harsh synth chord, such that this aggressive, synthetic sonority becomes causally associated with both the body and the blinking gesture depicted onscreen. In line with Michel Chion's notion of valeur ajouté ("added value"), this synth sonority becomes consummated by its close alignment (and, practically-speaking, its synchronisation) with the human body. $\frac{40}{}$ Valeur ajouté dictates that such sounds may consequently be interpreted as "naturally' [coming] from what is seen," and "already contained in the image itself." Mera points out that, just as this sonic quality becomes "narratively subsumed" into the onscreen body, notions of hapticity and embodied viewership also suggest that this synthesised sonority is "by extension subsumed into our bodies" as part of the embodiment and physiological stimulus that certain films encourage in their audiences. $\frac{42}{4}$

Based on the visibly exhaustive thought that went into 2049's sound design and sound editing, as well as the film's apparent optimisation for, and arguably showcasing of, its surround sound mix during its theatrical release, I believe that such a bodily and physiological engagement with the film was actively encouraged by its filmmakers. $\underline{43}$ Such scoring practices often challenge our definitions of what constitutes both score and sound design, with established distinctions between the two becoming indistinct. Composer Mica Levi, whose score for Under The Skin (Jonathan Glazer, 2017) has been 
similarly flagged for its haptic qualities, has spoken about this ambiguity. $\underline{44}$ She describes how "the lines between sound and music - at the moment, especially - are indistinguishable, which is really cool." 45 This is equally true of 2049 which, as we have said, boasts a continuous "timbral convergence" of score and sound throughout. $\underline{46}$ Crucially however, this blurring of distinctions is itself a central facet of the film's sonorous citation of Vangelis. Supervising sound editor Mark Mangini describes how this ambiguity was among the filmmakers' many conscious attempts to sonically cite Vangelis, based on his close examination of the original soundtrack stems for Blade Runner:

I think what I appreciate most about the first film is that it created moods using sound effects and music, and sometimes you didn't really know which was which. Having had the opportunity to investigate the sound effects stems and the music stems, I've discovered really interesting things about things that Vangelis had made that you thought were environmental textures that the sound designer had made, and vice versa - so there was that really beautiful cross-pollination that I thought we could achieve really effectively. $\underline{\underline{47}}$

For the 2049 sound team, the tool used to sonically cite Vangelis' "cross-pollination" was ultimately to be the hyperorchestra, as defined by Casanelles. Mangini explicitly describes his use of hyperorchestration techniques, referring to them as "sonic noodlings ... for lack of a better term," to create "brooding musical textures that would underpin almost every scene ... languid pads and tones that are reminiscent things that Vangelis had done in the first film that you didn't know were score." $\underline{8}$ These textures were generated by processing acoustic recordings of guitars, saxophones and even wind chimes beyond recognition, in much the same way Casanelles describes Trent Reznor and Atticus Ross' approach for scoring The Social Network (David Fincher, 2010) and that soundtrack's extensive processing of piano recordings to create musical variation. $\underline{49}$

These textures persist even in the film's most narratively benign dialogue scenes. Yet, playing into the film's haptic engagement, such instances of hyperorchestration are at their most effective when accompanying 2049's depictions of the body or graphic violence. This is perhaps most apparent in our first encounter with the film's antagonist, Niander Wallace (Jared Leto). In many ways this scene (beginning at 00:37:01) is typical of classical Hollywood film sound, particularly in its privileging of dialogue by way of prominent volume dips in the soundtrack. $\underline{50}$ However, the continual rumble that persists during Leto's monologue is made prominent by the unsettling actions it accompanies: the Blade Runner series' first and only depiction of a replicant birth; $\underline{\underline{11}}$ Niander's repellent handling of the new replicant's naked body; the kiss he forces upon her; and, horrifically, his immediate and seemingly irrational "retirement" of the replicant, by way of a surgical scalpel to the abdomen. Amid the distant and jarringly atonal hyperorchestrated sonorities that sits beneath the dialogue, a shrill and piercing synth emerges and performs a perfectly even descending semitone glissando, from $\mathrm{Ab}$ to $\mathrm{A}$ (begins at 00:38:40). As Casanelles reminds us, such even linear operations are virtually impossible in real-life 
performed music. $\underline{52}$ Such gliss. motions then, along with the constantly shifting, ambiguous tonal centre of the hyperorchestrated underscore, contribute a further layer of artificiality and discomfort to the scene and its disturbing depiction of Niander's creation, and blasé destruction, of artificial life. In much the same way that Mera's analysis of There Will Be Blood (Paul Thomas Anderson, 2007) emphasises the material reality of the score's instrumentation and its role in articulating the film's themes of "burial, emergence, death and rebirth," 2049's foregrounding of the materiality and practical realities of its hyperorchestrated score plays heavily into our haptic engagement with such scenes and their central themes. $\underline{53}$

Similar insights might be garnered from the scene depicting the brief cameo reappearance of a cloned Rachel, one of the protagonists from the original Blade Runner (this scene begins at 02:14:30). Interestingly, when Rachel's distinctive silhouette is first revealed, a prominent major fourth descent from $\mathrm{Db}$ to $\mathrm{Ab}$ can be discerned amid the ongoing "sonic noodling" (02:14:34), heard in a delicate hyperorchestral quality resembling violin harmonics or a glass harp. As I discuss in the next section, this major fourth interval was a crucial motivic particle of Vangelis' original score for Blade Runner and it permeates much of Zimmer and Wallfisch's contributions for its sequel. In this respect, just as the film's sound design and score become intermingled and indistinct (a conscious inclusion which is itself a citation of the original Blade Runner score, as Mangini reminds us), so too do the score's sonorous and motivic debts to Vangelis often comprise the same intermeshed citations. This prominent coexistence of both sonorous and melodic citations, with intervallic details subtly buttressing the overall textures of the film's underlying hyperorchestral sonority, furnishes us with a convincing illustration of the extent to which Zimmer and Wallfisch sought to interweave their score with the fabric of 2049, just as Vangelis did with his original score for Blade Runner. Furthermore, the presence of such citation during the film's highly-anticipated shot of a resurrected Rachel foregrounds and reaffirms the rebirth that Vangelis' musical material continually undergoes in 2049, often accompanying similar visual and narrative nods to Scott's original film.

In so many ways, 2049 is seen to foreground and reinforce these paradigms for embodied viewership and the multi-sensory nature of film sound, bringing to mind Laura Marks' earliest definitions of hapticity as "the way vision itself can be tactile, as though one were touching a film with one's eyes." $\underline{54}$ It is also important to note how, as well as harnessing the semiotic weight of timbre more generally, as argued by Smith and Turino, 2049 also capitalises on the existing semiotic capacity of the acoustic instruments that Vangelis' original synthesised sounds sought to emulate. With specific reference to Scott's original Blade Runner, Kalinak describes how the "martial heritage" of horns, with their associations with "pageantry, the military, and the hunt," has naturally led brass instrumentation to more triumphant, heroic appropriation in film, even in sci-fi texts. $\underline{55}$ This semiotic reliance on (synthesised) brass music is shared by both Blade Runner and its sequel, memorably distilled in the 
original film's opening pan across LA in which Scott's disturbing dystopian prophesy for the city is curiously conflated with the ethereal brass fanfares of Vangelis' "Opening Titles."

The way 2049 takes advantage of this synthesised brass instrumentation and timbre serves as a compelling final exemplar of Zimmer and Wallfisch's sonorous citation of Vangelis. This citation is conspicuously foregrounded by the contrasting ways that such significant instrumentation is employed in both films. While the first film's opening title scroll boasts an air of distant martial solemnity, this is quite consciously displaced in 2049 by a far shriller synth brass sonority that lacks any of the triumph or timbral warmth of its precursor. This contrast is rendered even more stark by its location in the film, situated after a prominent piano passage in the preceding prologue (material directly preceding the music transcribed in Figure 5; begins at 00:00:48). Although tonally ambiguous, the very presence of the piano during this brief prologue title card serves to communicate inherently natural and human qualities. With all piano music's associations with Romanticism, emotivity and even touch-sensitivity, as well as its role as what James Parakilas describes as a "cultural go-between" and its chameleonic capacity to "[impersonate] the sustained singing of the human voice," 2049's opening text scroll is lent a delicate expressivity and tangible human qualities. $\frac{56}{}$ However, as I note above, this effect is shortlived and it is quickly effaced by the score's opening synth power chord (see Figure 5, bar 1) during the film's first shot: the close-up of the opening human eye. Another visual cue drawn from Ridley Scott's original film, this shot garners new significance and is transformed by its sonority in 2049 . While the presence of the eye in the original Blade Runner's introduction places audiences in a perspective of spectatorial wonderment at the futuristic scene unfolding (encouraged by the warm synth pads of Vangelis), in 2049 the narrowed pupil we witness communicates only fear, underlined by its synchronisation to this aggressive synth chord. $\underline{57}$ While the exact melodic and harmonic distinctions between these two sequences will be explored in greater depth in the following section, the manner in which sonority links, and consequently transforms, these two scenes speaks volumes of 2049's conscious sonorous debts to its precursor and, crucially, its establishment and violation of expectations in forging the sequel's more barren first impression of Blade Runner's dystopian future.

Such foregrounding of sonority, tessitura, timbre, performance direction and instrumentation were to be the first vehicles employed by Zimmer and Wallfisch in order to create "something new, but still firmly rooted in that incredible sound world that Vangelis created." $\underline{58}$ However, beyond such issues of semiotics and sonority, the extent of 2049's equal reliance on explicit motivic adaptation of Vangelis merits similarly close scrutiny, however concealed this form of citation may at first appear. Deftly occluded amid their ongoing mutualistic discourse with the film's sound design and mixing, the score's many direct melodic and harmonic references to the original Blade Runner are often seen to undergo extensive motivic transformation such that they just tickle the perimeter of our recognition. In the following section, I will attempt to trace some of these covert relationships and how they interact with the film's classical narrative qualities. 


\section{(ii) Motivic Citation}

In the case of texts like this which are so strongly characterised by timbre, production value, sound processing and synthesis, the use of traditional musical analysis as the primary means of describing musical experience is often called into question. $\frac{59}{}$ However, although I have framed 2049 as an archetype for the importance of timbre and instrumentation in contemporary scoring, I believe a more integrated approach is essential to reveal the extent and intricacies of Zimmer and Wallfisch's citational practice, incorporating more traditional musical analysis alongside the contemporary paradigms I have explored above. As such, this section comprises in-depth harmonic and thematic analyses of Zimmer and Wallfisch's score, allowing us to more precisely trace and account for their elaborate transformations of Vangelis' original Blade Runner score.

So then, what characteristics best constitute what Rudolph Reti would call the "identical musical substance" that the soundtrack of both Blade Runner and its sequel share? $\frac{60}{6}$ Let's first turn to Vangelis' "Opening Titles" from the original film:

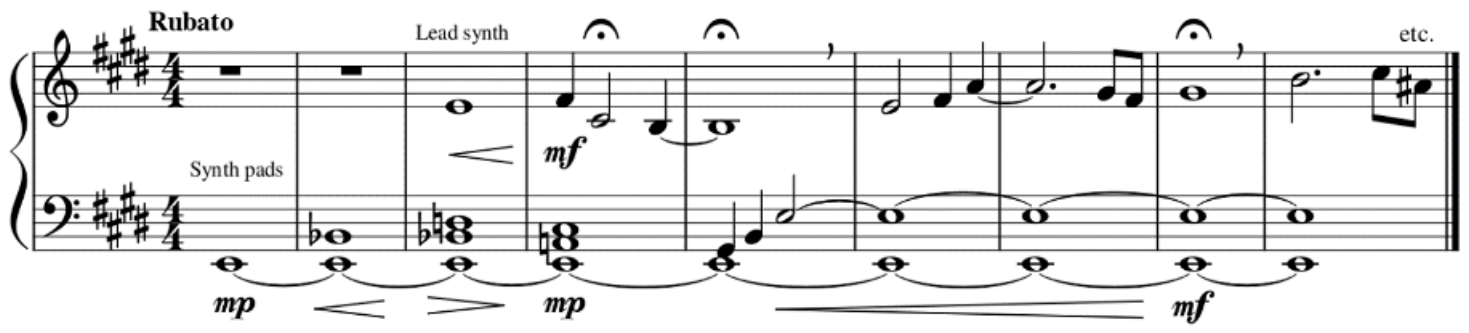

Figure 3. Piano reduction of Vangelis' “Opening Titles” from Blade Runner (begins at 00:03:13).

Motivically speaking, the essence of this track might be broken down into two constituent defining motifs or particles:

i)

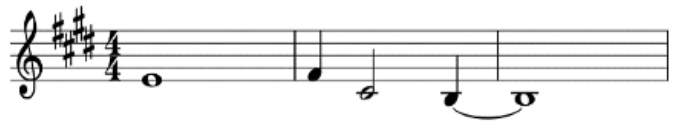

Figure 4. Motivic particles that constitute “Opening Titles" from Blade Runner (1982). ii)

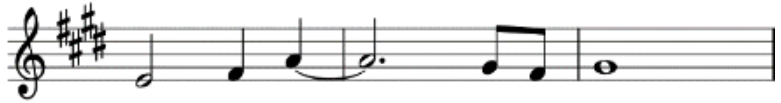

Disregarding the quaver movement in Motif (ii) as a sort of fanfare-like ornament, we might take both motifs as two very recognisable four-note phrases. Motif (i) begins with a major $2^{\text {nd }}$ ascent from the tonic $(\mathrm{E}-\mathrm{F} \#)$, before falling a perfect $4^{\text {th }}$ to the submediant $(\mathrm{C} \#)$ and then a $2^{\text {nd }}$ to the dominant $(B)$. This last descending motion (from $\mathrm{C} \#-\mathrm{B}$, submediant to dominant) is perhaps the most recognisable 
element of Motif (i). Similarly, Motif (ii) begins with a major $2^{\text {nd }}$ ascent from the tonic, before departing from the first motif in its cadential fall from the subdominant to mediant (A-G\#) which, in its prominent third harmony, emphasises the decidedly major tonality of "Opening Titles." This major $3^{\text {rd }}$ may well be considered a signifier of Vangelis' score at large, especially given sense of optimism and natural expansiveness that it confoundingly communicates amid the distressing dystopian skyline of the film's opening sequence.

Turning to 2049, let's begin with the film's equivalent title sequence and its accompanying score, simply titled "2049." The deliberateness with which the film's opening visually cites the 1982 sequence is very transparent from the outset, yet its musical citation is not so immediately apparent:

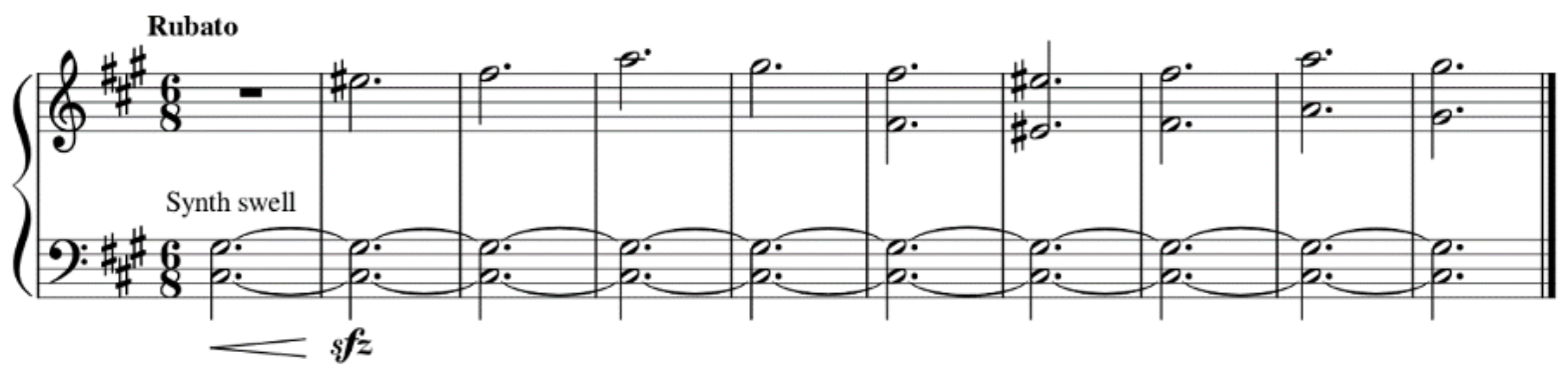

Figure 5. Piano reduction of Zimmer and Wallfisch's cue "2049" from 2049 (begins at 00:01:53).

This cue sounds immediately at odds with the music of the equivalent title scroll from 1982. However, despite the markedly more sparse and barren qualities, both visually and in the accompanying soundtrack, perhaps the first distinguishable nod to Vangelis' score is to be found in the E\# accidentals dotted throughout this track. The excerpt of "2049" transcribed above is preceded by chromatic, ambiguous harmonies that undermine any sense of tonal stability (see Figure 6). However, when it eventually arrives, the "2049" theme implies a key of F\# Minor through a dominant pedal on C\# and

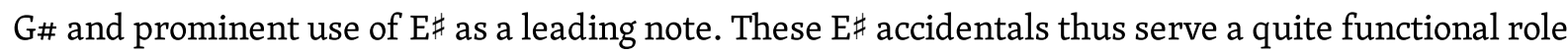
within the cue's apparent minor mode. However, more importantly, the presence of these E\# accidentals throughout the cue enables " 2049 " to communicate the same $4^{\text {th }}$ to $3^{\text {rd }}$ descent that was so central to Motif (ii) of Vangelis' 1982 “Opening Titles": the synth brass fanfare-like ornament that we have said was vital in conjuring original film's juxtaposition of natural expansiveness and oppressive dystopia.

While in Vangelis' "Opening Titles” this resolve takes the form of an A-G\# descent from the subdominant to the mediant (encased in an unambiguous E Major tonic chord), in "2049" this F\#-E\# descent from the tonic to leading-tone (heard alongside a dominant pedal) acts as an equivalent 
cadential fall: this time, a fall to the major $3^{\text {rd }}$ of a $C \#$ Major chord, creating an imperfect cadence in $F \#$ Minor. The result of this close (but not quite) equivalency is an unsettling, uncanny quality: Vangelis "Opening Titles" cue is unambiguous in its E Major tonality; by contrast, Zimmer and Wallfisch's opening for 2049 generates tension, with its melody sitting upon what sounds like a tonic pedal, but one which behaves like a dominant pedal. This unsettling effect is heightened by the preceding piano section (see Figure 6) which, as we have said, roves through a highly ambiguous progression chords and, in so doing, has already undermined our confidence in " 2049 " having a definite tonality at all:

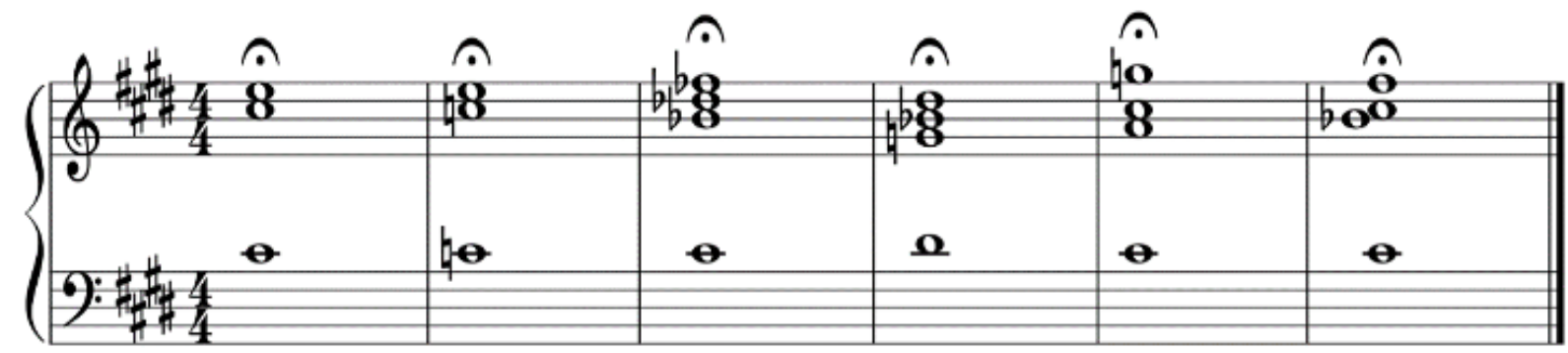

Figure 6. Excerpt from Zimmer and Wallfisch's cue "2049" from 2049 (begins at 00:00:48), illustrating the ambiguous piano chords preceding the material transcribed in Figure 5.

Although occluded amid this carefully woven veil of tonal ambiguity, it soon becomes apparent that the cue "2049" is entirely based around Motif (ii) of Vangelis' "Opening Titles" and follows the same fournote melodic contour, as Zimmer and Wallfisch's score both harnesses the musical material of Vangelis yet simultaneously obscures it from view. This prominent motivic material from Blade Runner is audibly encrypted by way of the smallest variations: it is fragmented, in that only Motif (ii) is cited; the melody line is heard an octave higher, shrouded in an apparent minor tonality; it is performed with a much more shrill, piercing synthesizer; " 2049 " is performed at a much slower, free tempo than "Opening Titles"; and, crucially, it begins on a different degree of the scale. We have already said that "2049" affords us a short-lived moment of familiarity amid its ambiguous melodic ramblings (when its F\#-E\# descent creates a major $3^{\text {rd }}$ cadential resolve, like that of Vangelis' “Opening Titles"). However, although the melody lands on this major $3^{\text {rd }}$ within an apparent $C \#$ Major chord, should we still assume that the "2049" cue's tonality is in F\# Minor then the melody instead lands on the leadingtone at the end of each four-note phrase, by contrast with the recognisable mediant which is so emblematic of Vangelis' triumphant opening.

This last point is crucial because, despite the unfamiliar territory that this divergence seems to establish in "2049," it is in fact responsible for the most obvious - yet hidden - equivalence between the two films' opening cues. Vangelis' opening is firmly established in the key of E Major, while it is heavily implied that " 2049 " is a major $2^{\text {nd }}$ higher (with an apparent tonal centre of $F \#$ Minor). However, in the 
latter, because the melody begins on the leading-tone instead of the tonic, the opening phrases of both "2049" and Motif (ii) of "Opening Titles" share all but their first note (F\# - A - G\#). Even the divergent starting point of the "2049" melody ( $E \#$ instead of $E$ ) reflects just one small chromatic adjustment and is well within the scope of thematic variation described by Reti. This demonstrates how several small, yet well-placed variations almost completely occlude our recognition of Vangelis' "Opening Titles." Similarly, it shows how, in these two equivalent openings, vastly different qualities of tension may be facilitated by "one identical musical substance" [1] and its new cadential and intervallic emphases. $\underline{61}$

Turning to another pivotal scene in 2049 which reveals the extent of the score's citation, we see Ryan Gosling's character $\mathrm{K}$ accept his journey and resolve to uncover the true nature of his parentage. The accompanying cue (entitled "Mesa") boasts far more explicit sonorous debts to Vangelis than my first example, and its thematic derivations are more explicit still:

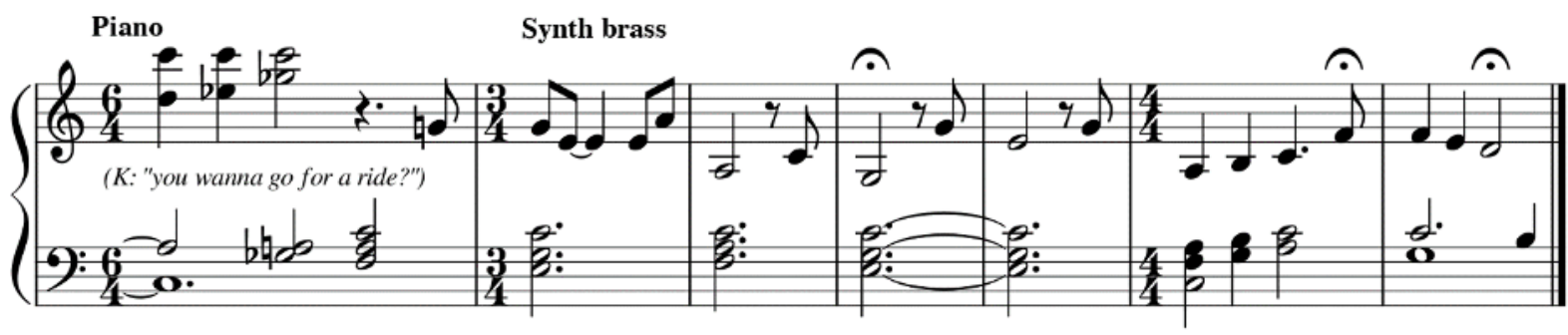

Figure 7. Excerpt from Zimmer and Wallfisch's cue “Mesa” from 2049 (begins at 00:57:35).

From the introduction of the synth brass melody, "Mesa" palpably mirrors Motif (i) in its first phrase's characteristic $6^{\text {th }}-5^{\text {th }}$ fall (A-G), while in its second phrase we clearly hear the $4^{\text {th }}-3^{\text {rd }}$ descent of Motif (ii), now in C Major:

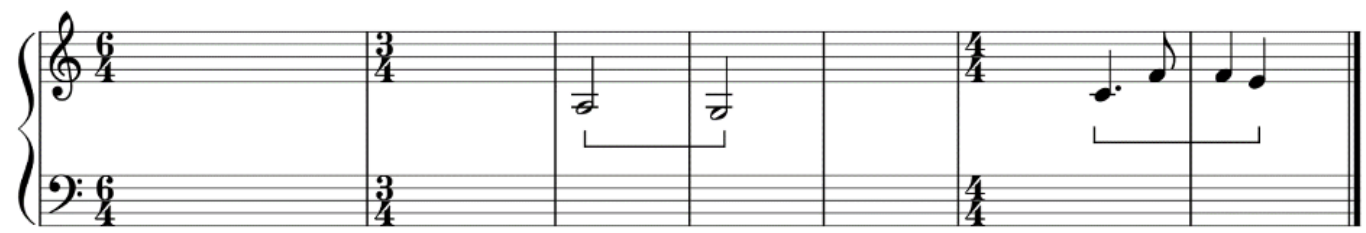

Figure 8. Excerpt from "Mesa," highlighting its debts to Motif (i) of Vangelis' "Opening Titles."

Furthermore, the perfect $5^{\text {th }}$ in the first phrase of "Mesa" (bars 2-4 in my transcription) comes off as a cognate inversion of the $4^{\text {th }}$ integral to Motif (i); and, perhaps most convincingly, the piano chords immediately preceding "Mesa" (just before the metre change in Figs. 7 - 9) incorporate the four-note phrase of the track "2049," transposed down a minor $3^{\text {rd }}$ and embedded in the harmony. Thus, the 
notes of the "2049" melody, itself a variation of Vangelis' Motif (ii), facilitate this importantly situated key change that directly coincides with K's pivotal acceptance of his journey:

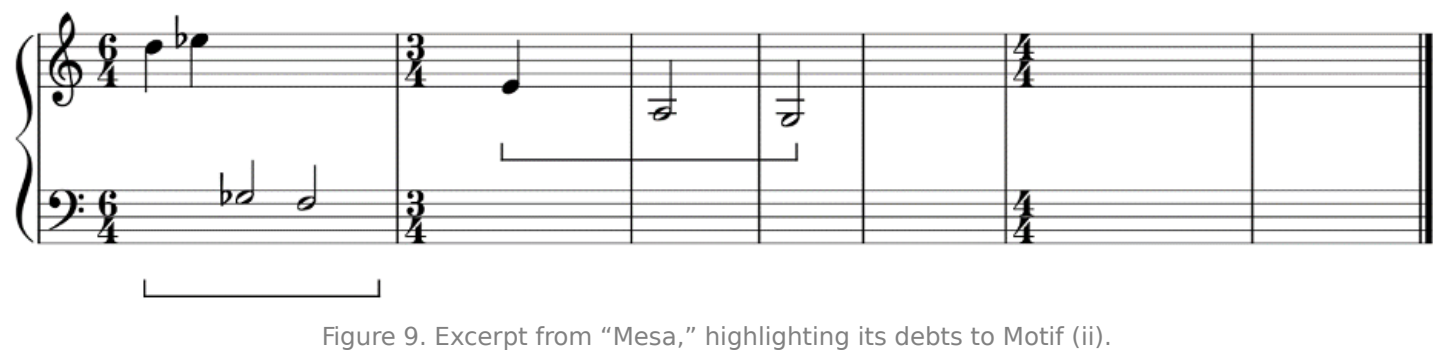

This more explicit citation of Vangelis heard in "Mesa" (which we might have expected of the film's opening sequence) appears to have been consciously postponed until the end of what we might consider the film's first act. Here, it serves a moment of far greater narrative importance. By recalling the opening moments of the 1982 film at a point so far into 2049's narrative, the film is retrospectively lent an almost prologue feel up to this point, framing K's acceptance of his journey amid the overall trajectory of the narrative.

I believe that film's resolve to more explicitly cite Vangelis at this juncture points to the apparently meticulous consideration lent to every aspect of 2049's dramaturgy, as well as its structural and affective rhythms as part of the wider Blade Runner franchise. Equally it highlights how, even for a film like 2049, which was universally lauded as an innovative and "carefully engineered narrative puzzle," Hollywood film still plays to steadfast expectations for how its narratives should function. ${ }^{62}$ Despite the perceived modernity of the 2049 score and how the film's opening sequence's confounds audience expectations, this analysis of "Mesa" also reveals how closely 2049 and its soundtrack adhere to our more typical expectations for Hollywood film. The film's opening titles, first scene and introductory cue ("2049") garner the same overture roles as those of its predecessor (Blade Runner's "Opening Titles"), even if this is not as immediately recognisable as in Vangelis' synthesised fanfare-like pads. .63 Musically, "2049" boasts an introductory fortissimo synth chord, analogous to the first tutti orchestral hit we might expect of a Wagnerian Romantische Oper. Similarly, "2049" continues to introduce the primary motivic material that goes on to populate and characterise so much of Zimmer and Wallfisch's underscore. A macro-analysis of the soundtrack under these terms could reveal a great deal about how a number of the film's important cues punctuate important moments in the narrative and, coloured by markedly distinct timbres, facilitate and frame the film's introduction, development and denouement: in particular, the cues "2049," "Mesa" and "Tears In The Rain," the film's final musical theme. However, this has not been the preoccupation of this article; rather, by 
focussing on 2049's debts to its precursor, I have attempted to chart how Zimmer and Wallfisch's citational practice shapes this score and to account for the many narrative, affective and structural ramifications that are borne for audiences of 2049 as a result.

Having said that, it is of course imperative to revisit "Tears In The Rain," 2049's only direct (and credited) citation of Vangelis in the film's final moments. Having investigated the way that Vangelis' music is adopted as the compositional bedrock for the 2049 score, surreptitiously permeating all of Zimmer and Wallfisch's 2049 musical contributions, the presence of the familiar cue "Tears In The Rain" at this point might be re-evaluated as an integral facet of this same idiom. The cue is heard in its original tonality from Blade Runner (C Major) and comprises the same fundamental motivic material as Vangelis' "Opening Titles," motifs (i) and (ii), which we have said constitute so much of Zimmer and Wallfisch's 2049 score. This explicit quotation of Vangelis' material from the original Blade Runner in the sequel's final moments ultimately heralds the denouement of the storyline concerning $K$ 's parentage which, as we have said, began with "Mesa." While "Mesa" frames the beginning of this journey and the film's first act, this iteration of "Tears In The Rain" as the film's final cue marks its resolution. In this respect, Zimmer and Wallfisch's reconstruction of Vangelis' cue, which could so easily be dismissed as an unremarkable flaunt of the score's referentiality, might be more accurately appraised. Rather than viewing the cue as a plundering of the affective significance of its original narrative context, "Tears In The Rain" can instead be seen to function as an essential component of the structural, affective and musical framework which is established throughout 2049.

A more surface-level examination might reduce the direct quotation "Tears In The Rain" as a tackedon evocation of the original film, rather than having any sort of integrated role in the 2049 score. However, as this article's close harmonic scrutiny has revealed, this is neither the first sonic citation of Vangelis in Villeneuve's film, nor is it even the film's first evocation of this exact cue. Near the beginning of the film, we see K surprise his holographic girlfriend Joi (Ana de Armas) with an "emanator," a gift which enables her to travel outside the confines of their apartment for the first time (see figure 10). 


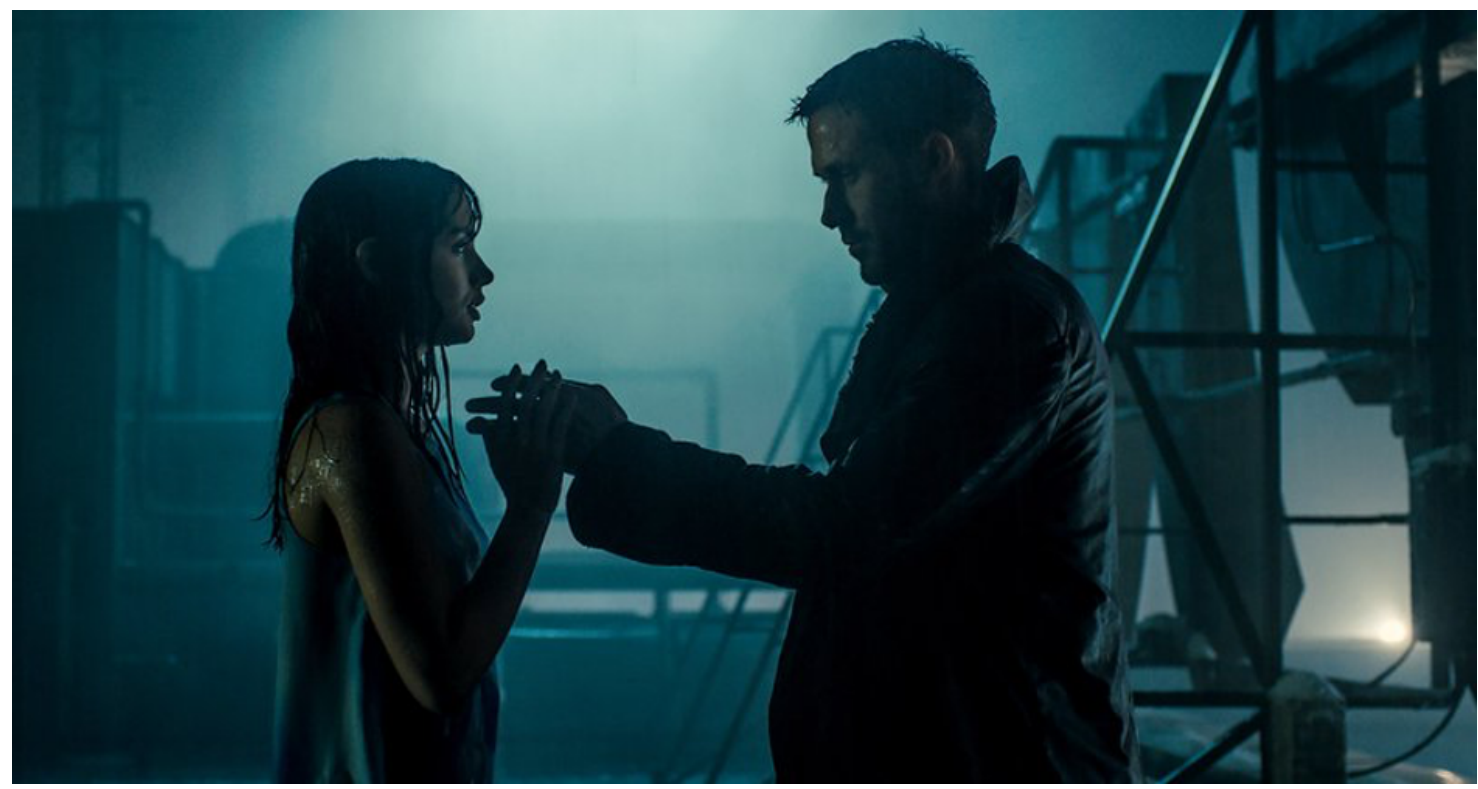

Figure 10. Using an "emanator," the hologram Joi (Ana de Armas) experiences rainfall for the first time, in a scene comprising some of 2049's many visual and sonic nods to the original Blade Runner (1982).

The scene that follows depicts Joi savouring her first experience of rainfall on her skin. This is an obvious visual cue pulled from the final scene of the original Blade Runner, in which defeated antagonist Roy Batty (Rutger Hauer) delivers the now iconic monologue from which Vangelis' cue “Tears In The Rain" derives its title. Zimmer's and Wallfisch's corresponding cue for this scene is similarly titled "Rain" and, although understated, is incontestable in its direct musical citation of “Tears In The Rain” from Vangelis' score. A new descending piano figure (beginning at 00:21:42) could lead one to believe this musical material to be original to 2049. However, this figure is a derivation on the first phrase of "Tears In The Rain" which, in itself, comprises identical motivic content to "Opening Titles" (transposed up a minor sixth, from E Major to C Major). A prominent hyperorchestrated C pedal (pitched at C6) persists throughout "Rain," as though persistently pre-empting the first note of Vangelis' cue (which never arrives). Similarly, the prominent C-D ascent from "Tears In The Rain" is heard in retrograde in the second and third notes of "Rain," and both the "Tears In The Rain" and "Rain" cues arrive at G:
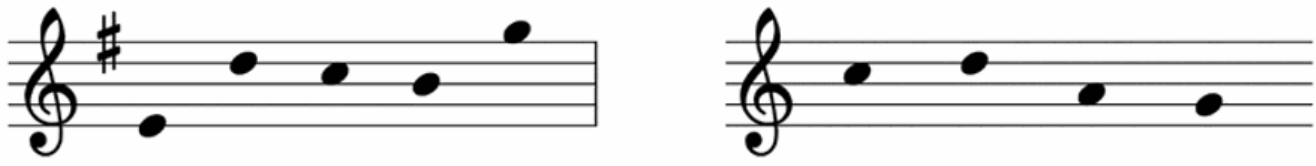
Perhaps the most convincing reflections of Zimmer's and Wallfisch's citation of "Tears In The Rain" cannot be distinguished within the context of the film, as they are disguised beneath the continual "hum" of Mangini's L.A. sonorities. $\underline{64}$ However, such occluded details are no less significant in our assessment of Wallfisch and Zimmer's appropriation of Vangelis for this analogous "Rain" scene and can provide a great deal of information surrounding the composition of the accompanying cue. Should we consult 2049's soundtrack album, the first chord of "Rain" can be clearly discerned and, formed from staggered synth pads, is tonally ambiguous. It initially sounds as a C9/G, teasing both the tonality and sonority of "Tears In The Rain." 65 However, when the piano figure enters (see Figure 11), the chord is revealed as a Gsus4, hinting at a potential tonal centre of G Major (the dominant of 'Tears In The Rain'):

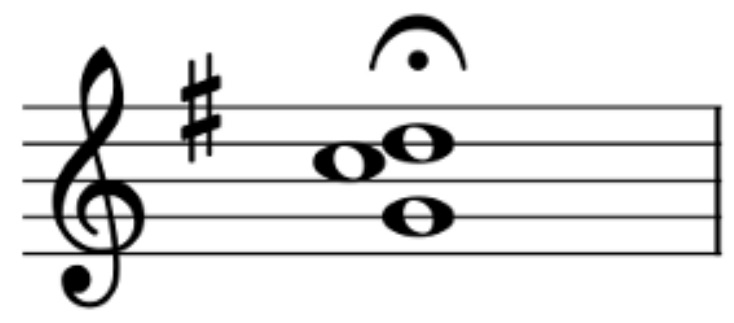

Figure 12. Ambiguous first chord of "Rain," as heard on the 2049 soundtrack release.

While these ties are arguably implicit, the most compelling evidence of Zimmer's and Wallfisch's citation of "Tears In The Rain" comes immediately after the first piano figure. Here, we hear the easilyidentifiable major fourth descent of Motif (i) in sustained strings, in its original tonic-to-dominant voicing (at 00:21:55 in 2049, or 00:44 on the soundtrack release). Perhaps most convincingly, a synth pad concurrently introduces a sustained supertonic note (unheard in the filmic context of 2049, being obscured under the scene's sound design, foley and ambient noise). Thus, the exact motivic content of "Tears In The Rain" is performed in its dominant key in "Rain," its notes divided and staggered across instrumentation. $\frac{66}{}$ All that is absent is the major second descent from the submediant to dominant: 


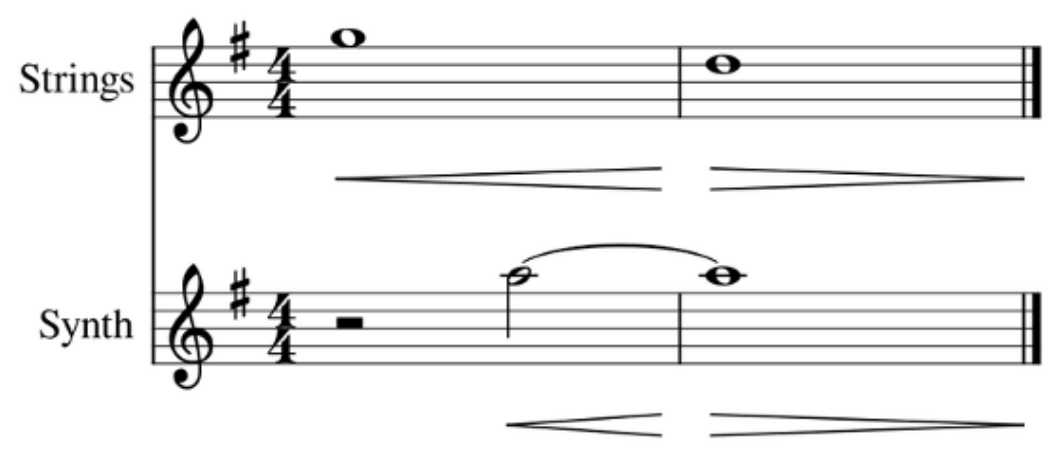

Figure 13. Derivation of Motif (i) in "Rain," its notes divided across instruments (at 00:44).

With all this in mind, I have reappraised the presence of "Tears In The Rain" at the conclusion of 2049 as a reprise. While this citation may once have been viewed as a more contrived relocation of musical material from one film's emotional centrepiece to that of its sequel, here it instead acts as a consummation of the motivic and harmonic material upon which Zimmer and Wallfisch surreptitiously founded their entire soundtrack, heard in fragmented form as early as the film's opening cue "2049." The cue "Rain" and its scene context renders this interpretation all the more compelling, especially given the apparent explicitness of the cue and its scene context's allusion to the original Blade Runner: visually, narratively, harmonically and motivically. It is also interesting to note that, on a macro level, "Rain" might be viewed as the middle of the Blade Runner series' three iterations of "Tears In The Rain." The first is heard in C Major, during Roy Batty's climactic speech; the middle iteration ("Rain") is in the dominant key of G Major, during this early 2049 scene; the final iteration accompanies the denouement of K's parentage arc at the end of 2049, once again in C Major. In this respect, given the presence of even such micro-level harmonic and motivic interrelationships unifying both Vangelis' score for Blade Runner and Zimmer and Wallfisch's heavily citational "continuation" of Vangelis' music (should we regard the score for the sequel as such), the claims I have made throughout this article regarding the unity between Zimmer and Wallfish's 2049 score and its 1982 precursor begin to seem all the more robust.

\section{Conclusion: (Re)arranged Marriages}

When first introduced to 2049's introductory title scroll, its minimalist typeface, sound design and sparse piano underscore, Villeneuve's sequel could initially be mistaken for a film which actively seeks to efface its debts to its source material. Yet, as I have argued throughout this article, even a cursory analysis of the film begins to reveal the extent of 2049's reliance on its precursor, the complex tendrils 
of which extend far beyond the film's handful of more explicit visual, narrative and melodic cues drawn from Blade Runner.

Having examined the myriad sonic and motivic citations that interact to constitute the 2049 score, there are several conclusions that we can draw about the film, its score and the contemporary approaches to the soundtrack which inform it. Firstly, it is remarkable to see the extent to which Villeneuve's resolve to move "closer to Vangelis" influenced this picture, from the musical and narrative creativity that this limitation served to spur, to the breadth of significance this citation lends even the most minute musical details. What's more, I hope that this article demonstrates how closely the film's sonic adaptation of the original Blade Runner film mirrors that of its narrative and visual adaptation, as musical material established by Vangelis in 1982 permeates the entire film, whether melodically, harmonically, intervallically or sonorously. As a result, the extent of 2049's adaptation of its source material is such that the film becomes altogether characterised by its stylised adaptation of its precursor, a quality which, as I have argued, renders 2049 much more stylistically similar to a remake than a sequel. Zimmer's and Wallfisch's complex transformations of Vangelis' music for the original Blade Runner serve only to enhance this impression.

Beyond the confines of Villeneuve's film, I believe that my observations on 2049 also have the potential to bear other more widely-applicable consequences, leading us to draw several important and more universal conclusions about the adaptation and rearrangement of pre-existing music in narrative film. Firstly, the 2049 score continually reaffirms the capacity of sonority as an important means of citation, variation and extra-narrative signification in cinema, representative of both the "hyperorchestral cinematic sound" of contemporary scoring that Casanelles so convincingly describes, in addition to the recurring notion of hapticity in film music, as described by Mera. $\frac{67}{}$ Secondly, I believe that by examining the structure established between both Blade Runner and 2049, we can clearly see the pivotal role that both sonic continuity and classical narrative structures play in our reception of the final audiovisual text. While Villeneuve's film was lauded for stylistic, visual and narrative innovation, 2049 serves as an important reminder of the expectations for classical narrative forms that Hollywood film closely adheres to, cultivates and perpetuates, if often just eluding our recognition. This macro-structural assessment of 2049's score also serves to refute other prevalent approaches to film music, which, according to Royal S. Brown, contend that "the film score rarely organises [its] sounds and devices into the type of extended, wholly musically coherent ... work that is one of the keystones of classical composing." $\underline{68}$

Above all, I believe that the musical citation of Blade Runner throughout 2049 highlights the eclectic array of creative consequences that musical adaptation can occasion in contemporary scoring practice. If we put the interrelationship between these two films to one side for a moment, I hope that this article has also illustrated how audience recognition of the cited material's source context is but one of 
a host of narrative, musical, structural and stylistic effects that musical adaptation can kindle in the creation of a soundtrack. Ultimately, it is the continual interaction of these many distinct effects which inform and constitute the final appearance and structure of 2049: a film which, though narratively a continuation of Ridley Scott's original film, is altogether characterised by its adaptation of source material established in its precursor thirty-five years before.

\section{Bibliography}

Bóas, Benedikt. “Jóhann settur af við gerð Blade Runner.” Vísir.is, August 9, 2017.

https://www.visir.is/g/2017170908918/johann-settur-af-vid-gerd-blade-runner-.

Brown, Royal S. Overtones and Undertones: Reading Film Music. Berkeley: University of California Press, 1994.

Burlingame, John. “Taking Sound and Music to Another Realm.” DGA Quarterly, Fall/Winter, 2016/17. https://www.dga.org/Craft/DGAQ/All-Articles/1701-Winter-2017/Collaborators-VilleneuveJohannsson.asp.

Casanelles, Sergi. "Mixing as a Hyperorchestration Tool." In The Palgrave Handbook of Sound Design and Music in Screen Media, edited by Liz Greene and Danijela Kulezic-Wilson, 57-72. London: Palgrave Macmillan, 2016.

Chion, Michel. Audio-Vision: Sound on Screen. Translated by Claudia Gorbman. New York: Columbia University Press, 1994.

Coulthard, Lisa. "Dirty Sound: Haptic Noise in New Extremism." In The Oxford Handbook of Sound and Image in Digital Media, edited by Carol Vernallis, Amy Herzog and John Richardson, 115-126. Oxford: Oxford University Press, 2013.

Demers, Joanna. Steal This Music: How Intellectual Property Law Affects Musical Creativity. Athens: University of Georgia Press, 2006.

Elsaesser, Thomas and Malte Hagener. Film Theory: An Introduction Through the Senses. London: Routledge, 2010.

Godsall, Jonathan. Reeled in: Pre-Existing Music in Narrative Film. New York: Routledge, 2019. 
Iceland Monitor. "Icelandic Composer to Write Musical Score for Blade Runner 2." Iceland Monitor, August 23, 2016.

https://web.archive.org/web/20161029012528/http://icelandmonitor.mbl.is/news/culture and living/ 2016/08/23/icelandic_composer_to_write_musical_score_for_blade/.

Kalinak, Kathryn. Settling the Score: Music and the Classical Hollywood Film. Wisconsin Studies in Film. Madison: University of Wisconsin Press, 1992.

Klein, Norman. “Building Blade Runner." Social Text, no. 28 (1991): 147-52.

Kulezic-Wilson, Danijela. Sound Design Is the New Score: Theory, Aesthetics, and Erotics of the Integrated Soundtrack. New York: Oxford University Press, 2019.

Marks, Laura. The Skin of the Film: Intercultural Cinema, Embodiment, and the Senses. Durham: Duke University Press, 2000.

Mera, Miguel. "Materialising Film Music.” In The Cambridge Companion to Film Music, edited by Mervyn Cooke and Fiona Ford, 157-172. Cambridge: Cambridge University Press, 2016.

Meyer, Leonard B. Style and Music: Theory, History, and Ideology. Chicago: University of Chicago Press, 1989.

Mullally, William. "Villeneuve reveals why he wanted David Bowie in Blade Runner 2049." Al Arabiya, September 28, 2017. https://english.alarabiya.net/en/life-style/2017/09/28/EXCUSIVE-Villeneuvereveals-why-he-wanted-David-Bowie-in-Blade-Runner-2049.html.

Parakilas, James. Piano Roles: Three Hundred Years of Life with the Piano. New Haven; London: Yale University Press, 2002.

Powrie, Phil. "The Fabulous Destiny of the Accordion in French Cinema." In Changing Tunes: The Use of Pre-Existing Music in Film, edited by Phil Powrie and Robynn Stilwell, 137-51. London: Ashgate, 2006.

Reti, Rudolph. The Thematic Process In Music. New York: The Macmillan Company, 1951.

Schroeder, David. Cinema's Illusions, Opera's Allure: The Operatic Impulse in Film. New York: Continuum, 2002.

Scott, A.O. “Review: In 'Blade Runner 2049,' Hunting Replicants Amid Strangeness.” The New York Times, October 2, 2017. https://www.nytimes.com/2017/10/02/movies/blade-runner-2049-reviewryan-gosling-harrison-ford.html. 
Smith, Jeff. "Bridging the Gap: Reconsidering the Border between Diegetic and Nondiegetic Music." Music and the Moving Image 2, no. 1 (2009): 1-25.

Smith, Jeff. The Sounds of Commerce: Marketing Popular Film Music. New York: Columbia University Press, 1998.

Summers, Tim. Understanding Video Game Music. Cambridge, United Kingdom; New York: Cambridge University Press, 2016.

Tapley, Kristopher. “'Arrival,' 'Jackie' Composers Push Boundaries of Music and Sound Design.” Variety, October 19, 2016. https://variety.com/2016/artisans/production/music-sound-arrival-jackie$\underline{1201892755}$.

Turino, Thomas. "Signs of Imagination, Identity, and Experience: A Peircian Semiotic Theory for Music." Ethnomusicology 43, no. 2 (Spring/Summer 1999): 221-55.

Caitríona Walsh, "Obscene Sounds: Sex, Death, and the Body On-Screen," Music and the Moving Image 10, no. 3 (2017): 36-54.

\section{Media Cited}

2001: A Space Odyssey. Directed by Stanley Kubrick. Film. California: Metro-Goldwyn-Mayer, 1968.

Blade Runner 2049. Directed by Denis Villeneuve. Film. California: Warner Bros., 2017.

Blade Runner. Directed by Ridley Scott. Film. California: Warner Bros. Pictures, 1982.

Coleman, Michael. “The Sound of Blade Runner 2049.” Online video, 14:08. October 20, 2017.

https://soundworkscollection.com/post/the-sound-of-blade-runner-2049.

GoldDerby. "Benjamin Wallfisch (Blade Runner 2049 composer) pays respect to original Vangelis score." YouTube video, 19:05. Streamed 19 October 2017. https://www.youtube.com/watch?v=ApHkgJQOSL4.

Talks at Google. "Blade Runner 2049 | Denis Villeneuve | Talks at Google.” YouTube video, 32:03.

September 29, 2017. https://www.youtube.com/watch?v=pPn-xuifKFg.

The Magnificent Ambersons. Directed by Orson Welles. Film. New York: RKO Pictures, 1942.

The Social Network. Directed by David Fincher. Film. California: Sony Pictures, 2010. 
Zimmer, Hans and Benjamin Wallfisch. Blade Runner 2049: Original Motion Picture Soundtrack. Epic/ASG. 2017, CD.

\section{Biography}

James Denis Mc Glynn is a conductor, composer and $\mathrm{PhD}$ Excellence Scholar at University College Cork. His research explores pre-existing music and narrative communication in the film score.

As an undergraduate, James founded the UCC Orchestra, resulting in his receipt of a coveted Quercus Creative \& Performing Arts Scholarship in 2015 and, upon graduating, a CACSSS PhD Excellence Scholarship. In 2017, he was selected to design music courses at the Tianmu Arts Training Centre in Suzhou, China, where he resided for several months. In 2018, James travelled to Paris to complete a three-month research residency at the Irish Culturel Centre, where he participated in renowned film sound scholar Michel Chion's 2018 'Audio-Vision' workshops.

Recently, James presented his research at NYU Steinhardt's 2019 and 2020 Music and the Moving Image conferences. In 2021, he will be performing the score in a forthcoming stage adaptation of Samuel Beckett's 'How It Is (Part 2),' starring Conor Lovett and Stephen Dillane (Game of Thrones, The Crown), as a member of the Irish Gamelan Orchestra. The 17-show residency will take place at the Coronet Theatre, London [date TBC, rescheduled due to COVID-19].

\section{otnotes}

1.

Iceland Monitor, “Iceland composer to write musical score for Blade Runner 2," Iceland Monitor, August

23,2016,https://icelandmonitor.mbl.is/news/culture_and_living/2016/08/23/icelandic_composer_to_ write_musical_score_for_blade/;

John Burlingame, “Taking Sound and Music to Another Realm," DGA Quarterly, Fall/Winter, 2016/17, https://www.dga.org/Craft/DGAQ/All-Articles/1701-Winter-2017/Collaborators-Vi\lleneuveJohannsson.aspx. $\doteq$ 
2. Benedikt Bóas, “Jóhann settur af við gerð Blade Runner," Vísir.is., August 9, 2017, https://www.visir.is/g/2017170908918/johann-settur-af-vid-gerd-blade-runner-. $\subseteq$

3. In an interview with Al Arabiya, Villeneuve described how “making movies is a laboratory. It's an artistic process. You cannot plan things. Jóhann Jóhannsson is one of my favourite composers alive today. He's a very strong artist. But the movie needed something different, and I needed to go back to something closer to Vangelis. Johan and I decided that I will need to go in another direction - that's what I will say. I hope I have the chance to work with him again because I think he's really a fantastic composer." William Mullally, "Villeneuve reveals why he wanted David Bowie in Blade Runner 2049," Al Arabiya, September 28, 2017, https://english.alarabiya.net/en/life-style/2017/09/28/EXCUSIVEVilleneuve-reveals-why-he-wanted-David-Bowie-in-Blade-Runner-2049.html. $\subseteq$

4. Mullally, "Blade Runner 2049."

5. Bóas, "Jóhann settur af við gerð Blade Runner."

6.

Kathryn Kalinak, Settling the Score: Music and the Classical Hollywood Film (Madison: University of Wisconsin Press, 1992), 155-157;

Jonathan Godsall, Reeled in: Pre-Existing Music in Narrative Film (New York: Routledge, 2019), 40-41.

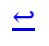

7. Jeff Smith, "Bridging the Gap: Reconsidering the Border Between Diegetic and Nondiegetic Music," Music and the Moving Image 2, no. 1 (2009): 24-25;

Royal S. Brown, Overtones and Undertones: Reading Film Music (Berkeley: University of California Press, 1994), 61;

Phil Powrie, "The Fabulous Destiny of the Accordion in French Cinema," in Changing Tunes: The Use of Pre-Existing Music in Film, ed. Phil Powrie and Robynn Stilwell (London: Ashgate, 2006), 137-138. 8. Jonathan Godsall, Reeled in: Pre-Existing Music in Narrative Film (New York: Routledge, 2019), 163.

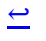

9. Despite the apparently routine use of "Tears In The Rain" in 2049, it will be important to revisit and re-examine the significance of this one direct quotation of Vangelis in the wake of the following analyses and observations. $\triangleq$

10. Joanna Demers, Steal This Music: How Intellectual Property Law Affects Musical Creativity (Athens: University of Georgia Press, 2006), 52. $\uplus$ 
11. Godsall, Reeled in, $8 . \bullet$

12.

Miguel Mera, "Materialising Film Music," in The Cambridge Companion to Film Music, ed. Mervyn Cooke and Fiona Ford (Cambridge: Cambridge University Press, 2016);

Lisa Coulthard, "Dirty Sound: Haptic Noise in New Extremism," in The Oxford Handbook of Sound and Image in Digital Media, ed. Carol Vernallis, Amy Herzog and John Richardson (Oxford: Oxford University Press, 2013);

Sergi Casanelles, "Mixing as a Hyperorchestration Tool," in The Palgrave Handbook of Sound Design and Music in Screen Media, ed. Liz Greene and Danijela Kulezic-Wilson, (London: Palgrave Macmillan, 2016);

Danijela Kulezic-Wilson, Sound Design Is the New Score: Theory, Aesthetics, and Erotics of the Integrated Soundtrack (New York: Oxford University Press, 2019), 3.

13. Norman Klein, “Building Blade Runner," Social Text, no. 28 (1991): 147.

14. Ibid., 147-148.

15. GoldDerby, "Benjamin Wallfisch (Blade Runner 2049 composer) pays respect to original Vangelis score," YouTube video, streamed live on October 19, 2017, https://www.youtube.com/watch? $\mathrm{v}=$ ApHkgJQOSL4.

16. Ibid. It is worth noting that, in various interviews after the announcement of his initial involvement in the project, Jóhann Jóhannsson spoke about the intended debts that his unused score would pay to Vangelis, with remarkably similar sentiments and wording to that of Wallfisch. See Burlingame, “Taking Sound and Music."

17. Talks at Google, "Blade Runner 2049 | Denis Villeneuve | Talks at Google," YouTube video, uploaded on September 29, 2017, https://www.youtube.com/watch?v=pPn-xuifKFg. $\boxminus$

18. Ibid. $\doteq$

19. GoldDerby, "Benjamin Wallfisch."

20. 
Leonard B. Meyer, Style and Music: Theory, History, and Ideology (Chicago: University of Chicago Press, 1989), 13-23;

See also Jeff Smith, The Sounds of Commerce: Marketing Popular Film Music (New York: Columbia University Press, 1998), 12.•

21. This hierarchy is arguably evident even in the very nature of western music notation. While prevailing approaches to music have long since moved away from late Romanticism's lionisation of the score, which dictates that "performances were merely imperfect manifestations of ... notated ideas" (Demers, Steal This Music, 34), western notated music still "neglects an extensive array of musical features that do not fit within the restrictions [it] impose[s]" particularly those qualities which it cannot easily represent with precision (timbre, sonority, density, performance direction, etc.), (Casanelles, "Hyperorchestration," 61). The natural hierarchy implied by this shortfall in traditional staff notation should be self-evident.

22.

Mera, "Materialising Film Music," 159;

Kulezic-Wilson, Sound Design, 90; Casanelles, "Hyperorchestration," 58.

23.

Kulezic-Wilson, Sound Design, 35.

This is another current discussion that has dominated film music scholarship over the past decade, with some going so far as to argue the process of musical composition is "a subset of sound design" (Casanelles, "Hyperorchestration," 62). The theoretical origins of this idea are in a perceived unity of the cinematic form across both film and music scholarship, a concept which has attracted comparison with Wagner's notion of gesamtkunstwerk (see Flinn 1992, 34; see also Davison 2004, 33). $\Xi$

24. Demers, Steal This Music, 52. $\leftrightarrows$

25. Indeed, this might be seen as analogous to Villeneuve's emphasis on the visual tone of the film, such that 2049 might be viewed as a complete tonal or sensory recreation of its source material, visually and sonically. $\subseteq$

26. GoldDerby, "Benjamin Wallfisch."

27. Burlingame, "Taking Sound and Music."

28. Casanelles, "Hyperorchestration," 58. 
29. Ibid. Adopting Baudrillardian approaches to simulacra and simulations, "hyperorchestral" is a term that has been used to describe acoustic sounds which have been manipulated to form sonorities that are irreproducible in reality. Hyperorchestration thus denotes "the processes of music creation that transcend the limitations of the physical world" and which, in doing so, transcend the representational capacity of the traditional score which is so often used in traditional musicology as "the primary source to describe a musical experience" (Casanelles, "Hyperorchestration," 58, 61)..

30. Thomas Turino, "Signs of Imagination, Identity, and Experience: A Peircian Semiotic Theory for Music," Ethnomusicology 43, no. 2 (Spring/Summer 1999): 236. Turino's semiotics of music, in contrast with musical binaries like those proposed by Meyer, contends that musical meaning is generated by the interaction of a multitude of constituent components. All of these elements act as "discrete icons" in isolation, yet continually intersect with adjacent qualities to generate new significance. In describing this multi-componential nature of music, he argues that "any musical unit is comprised of a number of components including pitch, scale type, timbre, rhythmic motion, tempo, melodic shape, meter, dynamics, harmony (where applicable), specific melodies, quotes, genres - all sounding simultaneously" (Turino, "Signs of Imagination," 236-37), such that any one feature might be foregrounded or withdrawn as a signifier as part of a continual flux of signification. $\subseteq$

31. Casanelles, "Hyperorchestration," $57 . \Leftarrow$

32. Klein, "Building Blade Runner," 147. $\subseteq$

33. Smith, The Sounds of Commerce, 10.

34. Gold Derby, “Benjamin Wallfisch." $\leftrightarrows$

35. Kalinak, Settling the Score, $188 . \unlhd$

36. Smith, The Sounds of Commerce, 10.

37.

Coulthard, "Dirty Sound";

Laura Marks, The Skin of the Film: Intercultural Cinema, Embodiment, and the Senses (Durham: Duke University Press, 2000), 145;

Mera, "Materialising Film Music."

38. Mera, "Materialising Film Music," 158. 
39. Such ocular imagery is recurrent in the extended Blade Runner canon. Similar "eye" shots are prominent in both films' introduction sequences and, narratively, the fictional Voight-Kampff eye test is the only way to identify the film's antagonists as "replicants" (bioengineered lifeforms almost indistinguishable from human beings). Similar imagery follows in the sequel: 2049's primary antagonist Niander Wallace (Jared Leto) is blind, and it is from eye colour alone that Deckard (Harrison Ford) distinguishes a cloned Rachel from the previous incarnation of his past love interest. $\Xi$

40. Michel Chion, Audio-Vision: Sound on Screen, trans. Claudia Gorbman (New York: Columbia University Press, 1994), 5.

41. Ibid. $\boxminus$

42. Mera, "Materialising Film Music," $167 . \subseteq$

43.

Michael Coleman, “The Sound of Blade Runner 2049," October 20, 2017, https://soundworkscollection.com/post/the-sound-of-blade-runner-2049.

The physiological impact of music has been long-acknowledged in scholarship and is frequently coopted in discussions on the effect of music in film. Kathryn Kalinak's monograph on classical Hollywood scoring memorably accounts for such issues of physiology: "One of the most demonstrable of the ways in which music can have a definite, verifiable, and predictable effect is through its physiological impact, that is, through certain involuntary responses caused by its stimulation of the human nervous system. The most important of these stimulants - rhythm, dynamics, tempo, and choice of pitch - provide the basis of physiological response";

Kalinak, Settling the Score, 8-9. Along with issues of dynamics and pitch, the opening of 2049 demonstrates the equal importance that timbre can have in eliciting such physiological stimuli. $\subseteq$ 44. See Caitríona Walsh, "Obscene Sounds: Sex, Death, and the Body On-Screen," Music and the Moving Image 10, no. 3 (2017): 36-54. $\subseteq$

45. Levi, quoted in Kristopher Tapley, “'Arrival,' 'Jackie' Composers Push Boundaries of Music and Sound Design," Variety, October 19, 2016, https://variety.com/2016/artisans/production/musicsound-arrival-jackie-1201892755.

46. Tim Summers, Understanding Video Game Music (Cambridge, United Kingdom; New York: Cambridge University Press, 2016), 126.

47. Coleman, “The Sound of Blade Runner 2049." 
48. Ibid. $\triangleq$

49. Casanelles, "Hyperorchestration," 57.

50. Kalinak, Settling the Score, 79.

51. Replicants are the series' fictional bioengineered lifeforms, created to live in servitude of

humans. The films' eponymous "blade runners" (Deckard in Blade Runner; K in 2049) are police force operatives who seek to "retire" rogue replicants.

52. Casanelles, "Hyperorchestration," 59.

53. Mera, "Materialising Film Music," 164. $\subseteq$

54. Marks, The Skin of the Film, xi. $\doteq$

55. Kalinak, Settling the Score, $13 . \leftrightharpoons$

56. James Parakilas, Piano Roles: Three Hundred Years of Life with the Piano (New Haven; London: Yale University Press, 2002), 4-5.

57. Although this prominent distinction is invariably the combined effect of sonority and montage, such a perceived change in temperament for 2049's equivalent eye imagery is invariably compounded by the disjuncture between audiences' expectations for a Blade Runner title scroll and that which prefaces 2049. The opening shot of the original film is memorably tempered by its major tonality and warm, open intervals of its score (communicative of a triumphant introductory brass fanfare). In 2049, these qualities are buried within a tonally and sonically unfamiliar composition, such that the cue is rendered disturbing in its fractured reincarnation and recontextualisation. $\subseteq$ 58. GoldDerby, “Benjamin Wallfisch.”

59. Casanelles, "Hyperorchestration," 61.

60. Rudolph Reti, The Thematic Process In Music (New York: The Macmillan Company, 1951), $4 . \triangleq$ 61. Ibid.

62. A.O. Scott, “Review: In 'Blade Runner 2049,' Hunting Replicants Amid Strangeness," The New York Times, October 2, 2017. https://www.nytimes.com/2017/10/02/movies/blade-runner-2049review-ryan-gosling-harrison-ford.html. $\subseteq$

63. 
For a comprehensive account of the functions shared by film title music and operatic overtures (and indeed, for a wider comparison of the cinematic and operatic mediums), see David Schroeder, Cinema's Illusions, Opera's Allure: The Operatic Impulse in Film (New York: Continuum, 2002), in particular, the chapter “Titles Music as Operatic Overture," 85-96.

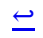

64. Klein, “Building Blade Runner," 147-148; Coleman, “The Sound of Blade Runner 2049.” $\doteq$ 65. Indeed, the introductory synth chords of both cues can be superimposed onto one another with a such remarkable degree of harmonic and sonorous consonance that they sound as one composition.

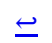

66. Equally, this is an exact minor third transposition of the first, second and fourth notes of Motif (i) from Vangelis' “Opening Titles” for Blade Runner (1982). $\subseteq$

67.

Casanelles, "Hyperorchestration," 58;

Mera, "Materialising Film Music," 159.

68. Brown, Overtones and Undertones, 48. 